
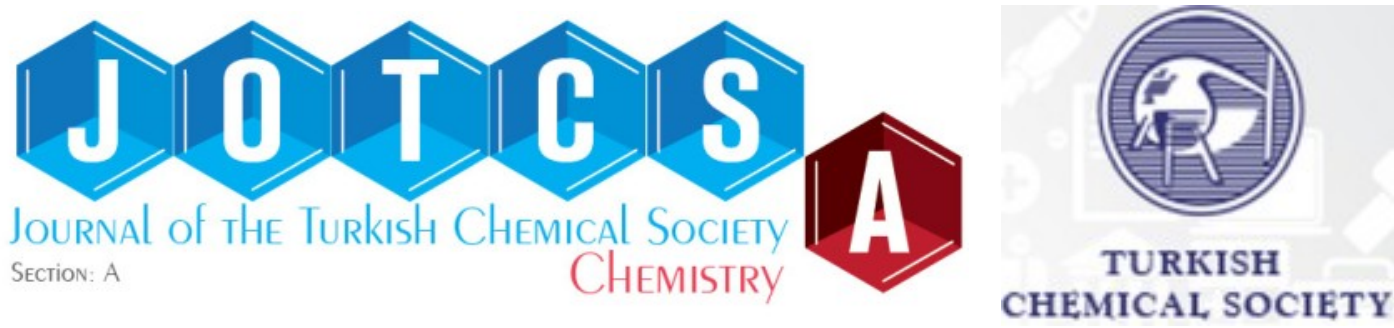

\title{
Evaluation of Corrosion Inhibition Properties of Pharmaceutically Active Compound Cefotaxime Sodium on Mild Steel Surface in Sulfuric Acid Medium
}

\author{
Sudhish Kumar SHUKLA* $\triangle(D$, Somya TANWER \\ Department of Chemistry, Manav Rachna University, Faridabad (INDIA)
}

\begin{abstract}
Cefotaxime sodium is applied in various concentrations in 0.55 yds sulfuric acid for the mild steel and analyzed through weight loss, potentiodynamic polarization, and electrochemical impedance spectroscopy studies from 298 to $338 \mathrm{~K}$. It gives better inhibition activity at lower temperature. Activation parameters, Gibbs free energy, enthalpy, and entropy of the reaction have been calculated. It was found that the inhibition process follows physical adsorption and the adsorption process follows Langmuir's adsorption isotherm. The inhibition behavior is supplemented by the surface study through atomic force microscopy and found that the inhibited surface has less roughness than the uninhibited surface.
\end{abstract}

Keywords: Eco-friendly inhibitors, weight loss, EIS, AFM.

Submitted: July 16, 2021. Accepted: September 22, 2021.

Cite this: Shukla S, Tanwer S. Evaluation of Corrosion Inhibition Properties of Pharmaceutically Active Compound Cefotaxime Sodium on Mild Steel Surface in Sulfuric Acid Medium. JOTCSA. 2021;8(4):1099110.

DOI: https://doi.org/10.18596/jotcsa.972325.

*Corresponding author. E-mail: sudhish.shukla@gmail.com.

\section{INTRODUCTION}

Corrosion is the natural phenomenon of the decadence of a material and its properties due to the synergy between the material and its active environment (1). The tendency of metal for corrosion to occur depends upon the surface structure and grain size, its chemical constituent, and the temperature of corrosive environment. Practically, the process of corrosion can be prevented rather than to eliminate completely. Corrosion plays a crucial role in environment, the mechanisms of corrosion is dependent upon the corrosive environment in which material surface is exposed. Corrosion depends upon these factors like metallic reactivity, presence of impurities in the metal, and corrosive medium, the presence of air, moisture, different corrosive gases like sulfur dioxide and carbon dioxide, and the presence of electrolytes (2). Corrosion is a critical and major industrial problem as it causes deterioration of metals and alloys in the presence of a corrosive environment generated by chemical or electrochemical pathways. Corrosion is an associate degree irrecoverable reaction of a metal, ceramic, or chemical compound with its surroundings which ends up in its consumption or dissolution into the fabric of a part of the surroundings (3-6). It causes significant loss to the total GDP of the nation. Corrosion costs more than 2.0 lakh crores of the Indian economy per year (7-9). Corrosion costs glaring in the form untimely decadence or necessary maintenance failures, repairs, and replacement of damaged parts. Corrosion inhibition can be employed by using chemicals, however almost all chemicals/substances start corrosion in the presence of air, water and soil $(10,11)$.

A chemical which, when added to a corrosive environment and hence reduces the rate of reaction of metal with its corrosive environment, is referred to as a corrosion inhibitor. Corrosive control of metals is aesthetically, economically, environmentally, and technically important (12). The inhibitor used is the best option to protect metals and alloys but there are some major 
limitations of organic inhibitors which have leads to the development of green and sustainable inhibitor materials towards control the metal corrosion as they are less toxic, biodegradable, cost-effective, and ecologically acceptable. To replace these toxic and hazardous inhibitors with less toxic and less hazardous inhibitors, many research groups work on developing an environmentally benign sustainable non-toxic corrosion inhibitor likely to have oxygen, nitrogen, and sulfur-like heteroatoms. Numerous natural products and their applications as a corrosion inhibitor, especially in steel, are discussed. Green inhibitors (13) are a need of the time. Research on corrosion has been an interesting topic for quite a long time. Green inhibitors are an old dream in applied corrosion in industrial practice, but one of the challenges is to guarantee or to trust in the chemical stability of the compound. Most of the research groups infer that the inhibitor concentration required is on the higher side but it has its own disadvantages: The higher concentration cannot be guaranteed in real applications over a longer period of time. High concentrations of inexperienced (organic) corrosion inhibitors (14-16) may scale back the barrier properties of a coating and should be not even compatible with the organic coating etc.

In the last few decades, the drugs make their efficient role as a corrosion inhibitor which fascinates research attention. Literature review disclose that various types of drugs (antibacterial, antifungal, antibiotic, anti-malarial, analgesic, antidepressant, anti-hypertensive, antihistamine) have been efficaciously vibrant as feasible corrosion inhibitors for decreasing effect of corrosion on mild steel and other metals and metal alloys (17-20). The imminent sections deliver comprehensive overview of the application of drugs and the literature on their corrosion inhibition studies. Most widely used metal in industry is mild steel in structural requirements. Acids are used in industrial applications for the purpose of pickling and descaling, etc. To minimize the corrosion due to these activities, corrosion inhibitors play a significant role to protect the metallic surfaces. Among various types of corrosion inhibitors, organic compounds are the most successful and profitable corrosion inhibitors for the protection of metallic surfaces (21). The inhibiting molecule may be adsorbed on the metallic surface due to physical or chemical interactions or it may be the combination of both. Generally organic and inorganic molecules act as corrosion inhibitors in practice are toxic in nature. Therefore, importance of the development of eco-friendly non-toxic corrosion inhibitors is the need of the day. In the current research, the development of corrosion inhibitors from commercially available drugs are used as corrosion inhibitors on metal surface owing to its low LD50 values $(19,22-28)$ in acidic media.
Cefotaxime sodium drug used in present study is a beta-lactam antibiotic classified as a third generation cephalosporin used to treat infections caused by bacteria. It is a cephalosporin organic sodium salt. Cefotaxime sodium is the commercial name of the sodium salt of [6R-[6-alpha,7beta(z)]]3-[(acetyloxy)methyl]-[[(2-amine-4-thiazolyl) (methoxyimino)acetyl]amino]-8-oxo-5-thia-1azabicyclo[4,2,0]oct-2-ene-2-carboxylic acid (29, $30)$. In this paper, investigation of the corrosion inhibition activity of expired cefotaxime sodium drug is investigated towards surface of mild steel in $0.5 \mathrm{M}$ $\mathrm{H}_{2} \mathrm{SO}_{4}$ using weight loss and electrochemical studies. Structure of the molecule is given in Figure 1 which has a molecular formula of $\mathrm{C}_{16} \mathrm{H}_{16} \mathrm{~N}_{5} \mathrm{NaO}_{7} \mathrm{~S}_{2}$.

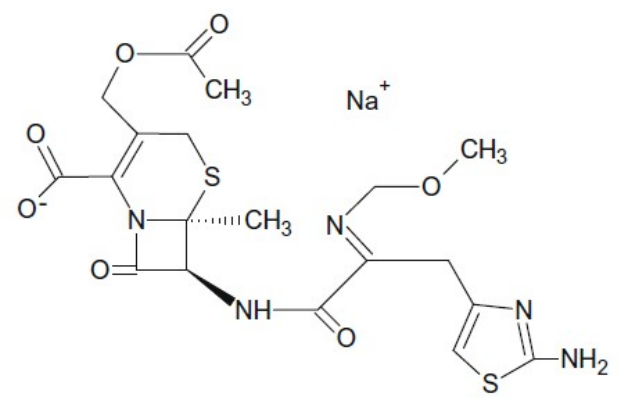

Figure 1: Chemical structure of cefotaxime sodium.

\section{EXPERIMENTAL}

\section{Inhibitor}

Cefotaxime sodium was procured from a common medicine shop and kept till the expiry date is over and the stock solution of this compound is made with water for all the experiments using dilution method for various concentrations of inhibitors (29)

\section{Corrosion measurements}

Corrosion measurements will be done on mild steel having composition (wt\%) $\mathrm{P}=0.03 ; \quad M n=0.035$; $\mathrm{C}=0.14 ; \mathrm{S}=0.025 ; \mathrm{Si}=0.17$; and Fe (remains). The mild steel surface duly cleaned by emery papers and cleaned with deionized water. Acetone is used for degreasing process and the samples were further dried in hot air blower and placed in desiccator for experiments.

\section{Weight loss technique}

This study is performed on mild steel of $10 \mathrm{~cm}^{2}$ area and having rectangular shape in $100 \mathrm{~mL}$ of acidic solution in various concentrations of inhibitors (from zero to optimum) at different temperature ranges. All the experiments were done in triplicate and the results are found to be a deviation of less than $0.1 \%$ which is due to manual error. To minimize the discrepancy, weight loss average in each condition has been taken in consideration for the calculation of different parameters. \%Inhibition efficiency, corrosion rate, surface coverage, and calculation of thermodynamic and adsorption parameters were calculated as mentioned in literature (31), (32). 


$$
\begin{aligned}
& \text { I.E. }(\%)=\frac{W_{0}-W_{i}}{W_{0}} \times 100 \\
& \Theta=\frac{W_{0}-W_{i}}{W_{0}}
\end{aligned}
$$

$\mathrm{W}_{\mathrm{o}}=$ weight loss of metal in the absence cefotaxime sodium,

$W_{i}=$ Weight loss in the presence of cefotaxime sodium

\section{Electrochemical techniques}

Polarization resistance, Tafel polarization, and EIS is conducted three electrode assembly where calomel electrode acts as reference electrode, platinum as the counter electrode, and metal sample for test as the working electrode. Working electrode area will be $1 \mathrm{~cm}^{2}$. Gamry Instruments potentiostat / galvanostat with Gamry frame work system on ESA 400 for all the electrochemical studies and analysis will be done through Echem analyst version 5.50 software packages for data fitting. All the measurements will be done with the parameters reported in literature $(21,33,34)$. All electrochemical studies like linear polarization, Tafel polarization and electrochemical impedance spectroscopy has been reproduces before reporting the results.

\section{RESULTS \& DISCUSSIONS}

\section{Weight loss measurements:}

Weight loss measurement of the metal strip is used to calculate inhibition efficiencies ( $\eta \%)$, corrosion rates $\left(C_{r}\right.$, in mmpy), and surface coverage $(\theta)$ for varying temperatures and they are reported in Table 1. Inhibition efficiency of the cefotaxime sodium increases with the increase in the inhibitor concentration from 0 to $4.5 \times 10^{-4} \mathrm{M}$. It was apparent from the Table 1 that while varying the temperature from $298 \mathrm{~K}$ to $338 \mathrm{~K}$ of $0.5 \mathrm{M} \mathrm{H}_{2} \mathrm{SO}_{4}$ solution, efficiency of inhibitor was always the highest at $4.5 \times 10^{-4} \mathrm{M}$ inhibitor percentage whereas increasing the percentage of drug in concentration makes negligible change in efficiency either in positive or negative data change. The maximum inhibitor efficiency was found at $289 \mathrm{~K}$ to be $95.7 \%$, but it seems to be decreasing at various increasing temperature change in $4.5 \times 10^{-4} \mathrm{M}$ inhibitory mixture, so $4.5 \times 10^{-4} \mathrm{M}$ inhibitory percentage was found to be the best suited amount in mixture to provide $95.5 \%$ inhibitory efficiency at $298 \mathrm{~K}$ temperature. This inhibitory action is caused by the molecular adsorption of cefotaxime sodium on the surface of mild steel. Adsorption may be due to both n-electrons and non-bonding lone pair of electrons. These properties can also be responsible for the inhibitive action. The same has been plotted in Figures 2 and 3 report the required inhibitor efficiency at varying temperature range of mixture with respect to inhibitor efficiency and corrosion rate, respectively.

Table 1: Weight loss measurement data in absence and presence of cefotaxime sodium in towards mild

\begin{tabular}{|c|c|c|c|c|c|}
\hline $\begin{array}{l}\text { Temperature } \\
\text { (K) }\end{array}$ & $\begin{array}{l}\text { Concentration } \\
\text { of inhibitor (M) }\end{array}$ & $\begin{array}{l}\text { Weight loss } \\
\text { (in } \mathrm{mg} \mathrm{cm}^{-} \\
\text {1) }\end{array}$ & $\begin{array}{l}\text { Inhibition } \\
\text { efficiency } \\
\text { (n) }(\%)\end{array}$ & $\begin{array}{l}\text { Corrosion } \\
\text { rate }\left(C_{r}\right) \\
(\mathrm{mm} / \mathrm{y})\end{array}$ & $\begin{array}{l}\text { Surface } \\
\text { coverage } \\
(\theta)\end{array}$ \\
\hline \multirow{10}{*}{298} & Blank & 14.00 & - & 52.14 & - \\
\hline & $0.5 \times 10^{-4}$ & 5.59 & 60.1 & 20.81 & 0.601 \\
\hline & $1.0 \times 10^{-4}$ & 4.54 & 67.6 & 16.89 & 0.676 \\
\hline & $1.5 \times 10^{-4}$ & 3.42 & 75.6 & 12.72 & 0.756 \\
\hline & $2.0 \times 10^{-4}$ & 2.60 & 81.4 & 9.70 & 0.814 \\
\hline & $2.5 \times 10^{-4}$ & 1.97 & 85.9 & 7.35 & 0.859 \\
\hline & $3.0 \times 10^{-4}$ & 1.39 & 90.1 & 5.16 & 0.901 \\
\hline & $3.5 \times 10^{-4}$ & 0.95 & 93.2 & 3.55 & 0.932 \\
\hline & $4.0 \times 10^{-4}$ & 0.63 & 95.5 & 2.35 & 0.955 \\
\hline & $4.5 \times 10^{-4}$ & 0.60 & 95.7 & 2.24 & 0.957 \\
\hline \multirow{10}{*}{308} & Blank & 17.17 & - & 63.94 & - \\
\hline & $0.5 \times 10^{-4}$ & 8.03 & 53.2 & 29.92 & 0.532 \\
\hline & $1.0 \times 10^{-4}$ & 6.40 & 62.7 & 23.84 & 0.627 \\
\hline & $1.5 \times 10^{-4}$ & 4.87 & 71.7 & 18.13 & 0.717 \\
\hline & $2.0 \times 10^{-4}$ & 3.67 & 78.6 & 13.66 & 0.786 \\
\hline & $2.5 \times 10^{-4}$ & 2.97 & 82.7 & 11.05 & 0.827 \\
\hline & $3.0 \times 10^{-4}$ & 2.27 & 86.7 & 8.44 & 0.868 \\
\hline & $3.5 \times 10^{-4}$ & 1.73 & 89.9 & 6.46 & 0.899 \\
\hline & $4.0 \times 10^{-4}$ & 0.97 & 94.4 & 3.60 & 0.944 \\
\hline & $4.5 \times 10^{-4}$ & 0.97 & 94.4 & 3.60 & 0.944 \\
\hline \multirow{4}{*}{318} & Blank & 26.05 & - & 97.01 & - \\
\hline & $0.5 \times 10^{-4}$ & 13.44 & 48.4 & 50.06 & 0.484 \\
\hline & $1.0 \times 10^{-4}$ & 11.62 & 55.4 & 43.27 & 0.554 \\
\hline & $1.5 \times 10^{-4}$ & 9.87 & 62.1 & 36.77 & 0.621 \\
\hline
\end{tabular}
steel in the aqueous solution of $0.5 \mathrm{M}$ sulfuric acid. 


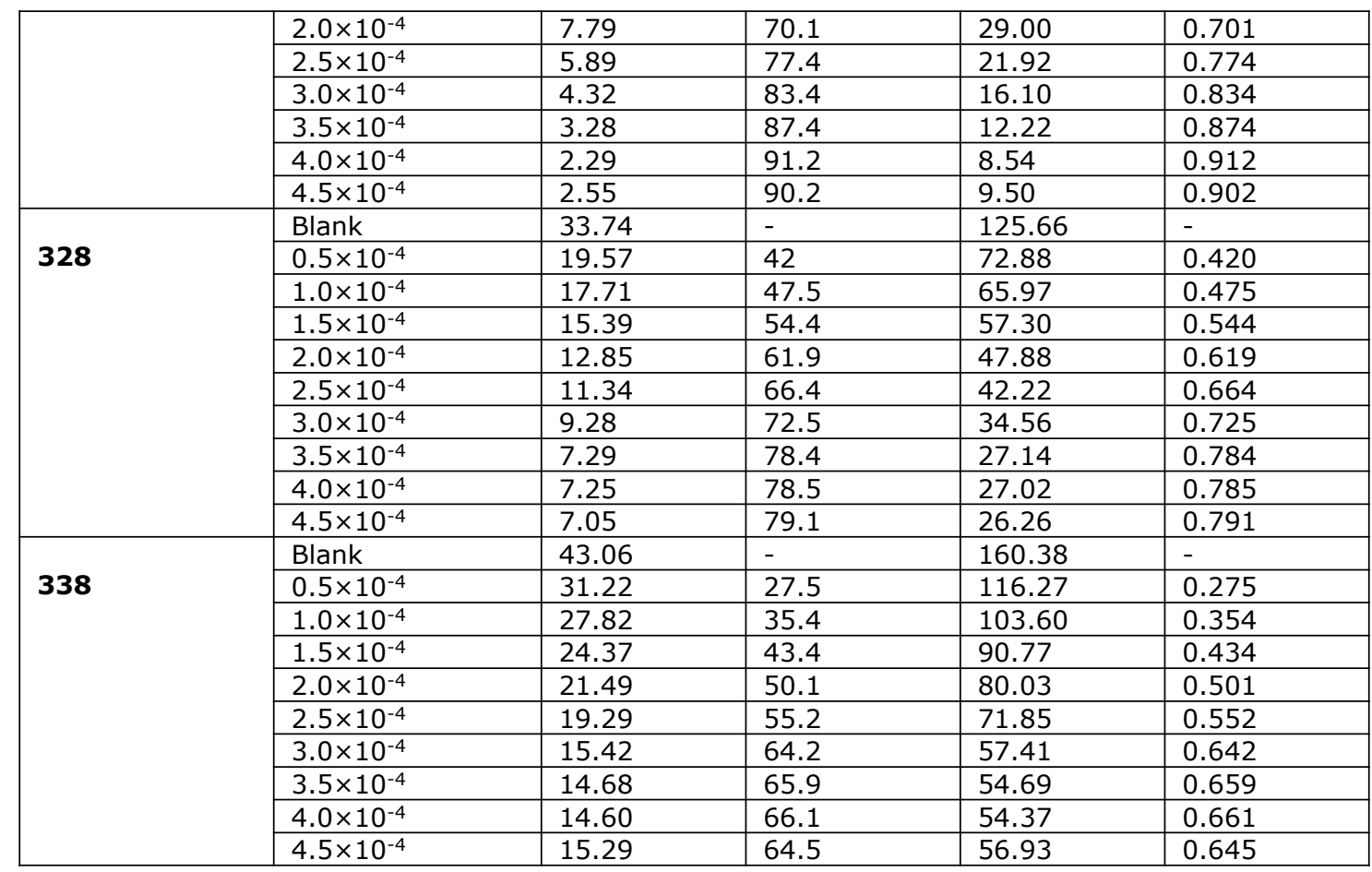

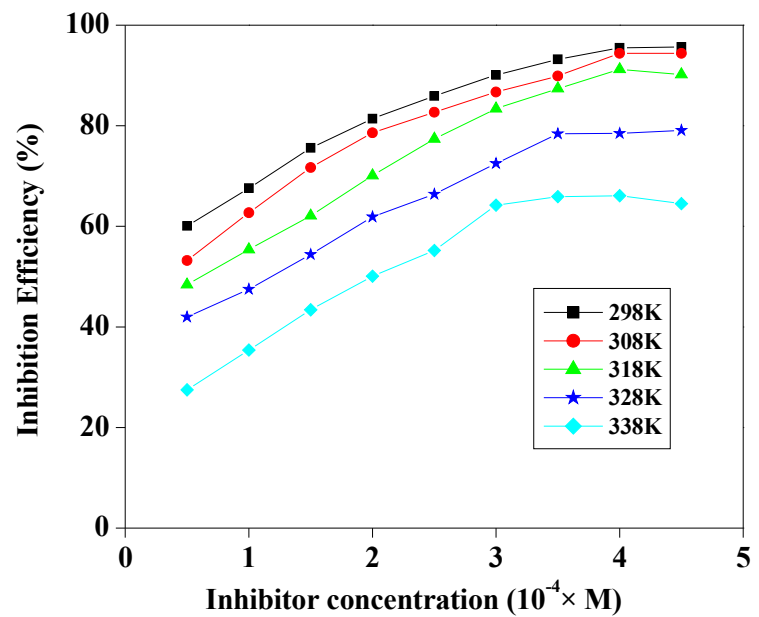

Figure 2: Inhibitor efficiency at varying temperatures on standard find concentration of the inhibitor.

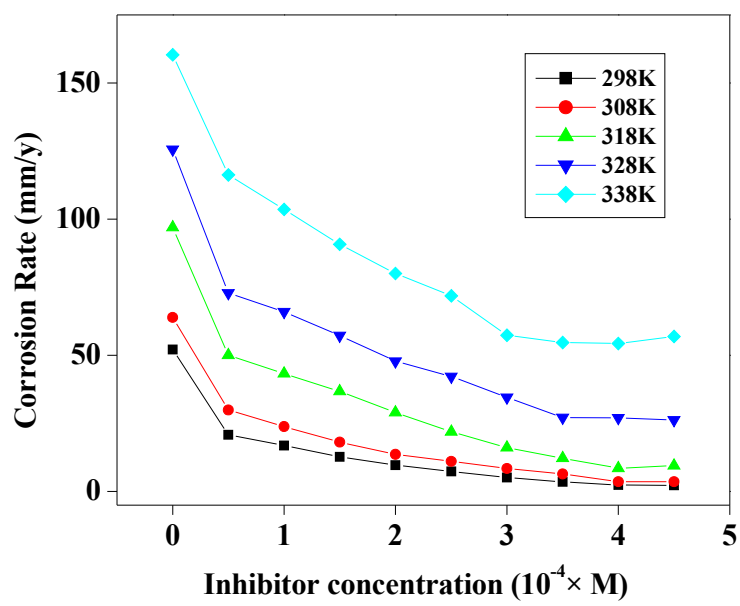

Figure 3: Corrosion rate at varying temperatures at various concentrations of cefotaxime sodium. 
Effect of solution temperature on the adsorption isotherm

It is crucial to understand how organoelectrochemical reactions work through adsorption isotherms. It was tested using different isotherms by $C_{\text {inh }}$ vs $C_{i n h} / \theta$ graph $(3,35)$, for the experimental results presented in this trial, Langmuir adsorption isotherm was considered adequate due to most linear representation of regression coefficient $\left(R^{2}\right)$. A mild steel plate, already discussed above, has been initiated for test in $0.5 \mathrm{M} \mathrm{H}_{2} \mathrm{SO}_{4}$ solution with $0.5 \times$ $10^{-4} \mathrm{M}$ inhibitor concentration in combination with the steel surface at a varying temperature range from $298 \mathrm{~K}-338 \mathrm{~K}$ and represented in Figure 4, which shows the linear regression coefficient and slope of the graph. The values of $\mathrm{R}^{2}$ listed in Table 2 range from 0.99765 to 0.98973 to extend the temperature range of the mixture from 298-338 $\mathrm{K}$. Due to the presence of $\pi$-electrons, and a quaternary nitrogen atom, it has proved perfectly suited for $4.0 \times 10^{-4} \mathrm{M}$ at a temperature of $298 \mathrm{~K}$ at the MS surface. Desorption of inhibitor may be the reason for this phenomenon. The $-\Delta G_{\text {ads }}$ values have been calculated and reported in Table 2, and they are between $31.13 \mathrm{~kJ} \mathrm{~mol}^{-1}$ to $38.34 \mathrm{~kJ} \mathrm{~mol}^{-1}$, corresponding to a range of 20 to $40 \mathrm{~kJ} \mathrm{~mol}^{-1}$. This suggests that the inhibitor is adsorbed on the metal surface is physically (36).

Table 2: Adsorption parameters of cefotaxime sodium on mild steel surface at different temperature ranges.

\begin{tabular}{|c|c|c|c|c|}
\hline Temperature (K) & $\begin{array}{c}\text { Kads } \\
\left(\mathbf{M o l}^{-1}\right)\end{array}$ & Slope & $\mathbf{R}^{\mathbf{2}}$ & $\begin{array}{c}-\mathbf{\Delta G} \text { ads } \\
\left(\mathbf{K J ~ m o l}^{\mathbf{1}} \mathbf{)}\right.\end{array}$ \\
\hline 298 & $5.1 \times 10^{3}$ & 0.94 & 0.99765 & 31.13 \\
\hline 308 & $6.4 \times 10^{3}$ & 0.92 & 0.99793 & 32.72 \\
\hline 318 & $8.5 \times 10^{3}$ & 0.92 & 0.99332 & 34.56 \\
\hline 328 & $9.9 \times 10^{3}$ & 1.04 & 0.99281 & 36.07 \\
\hline 338 & $1.5 \times 10^{4}$ & 1.16 & 0.98973 & 38.34 \\
\hline
\end{tabular}

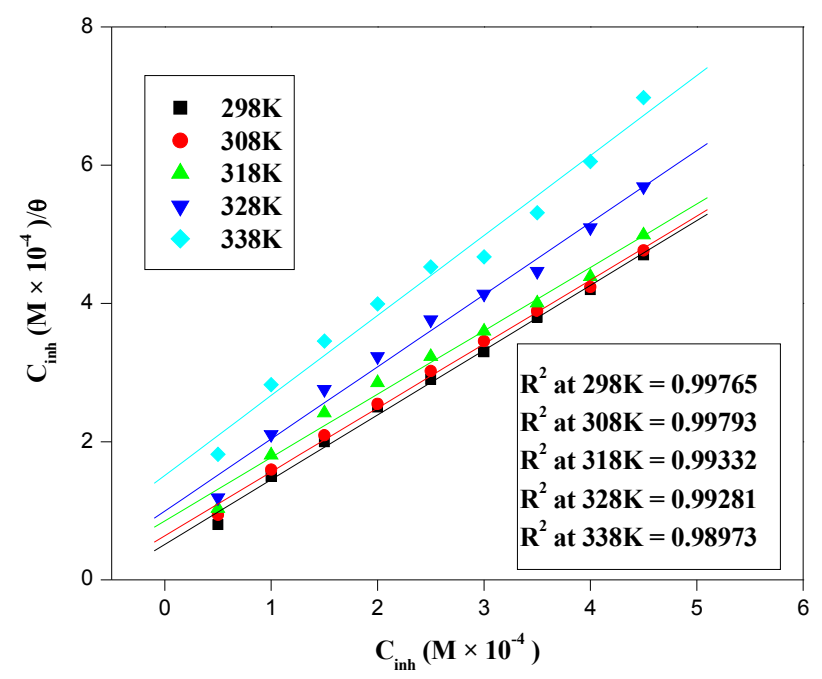

Figure 4: Langmuir's adsorption isotherm for different concentrations of cefotaxime sodium in $0.5 \mathrm{M}$ sulfuric acid solution.

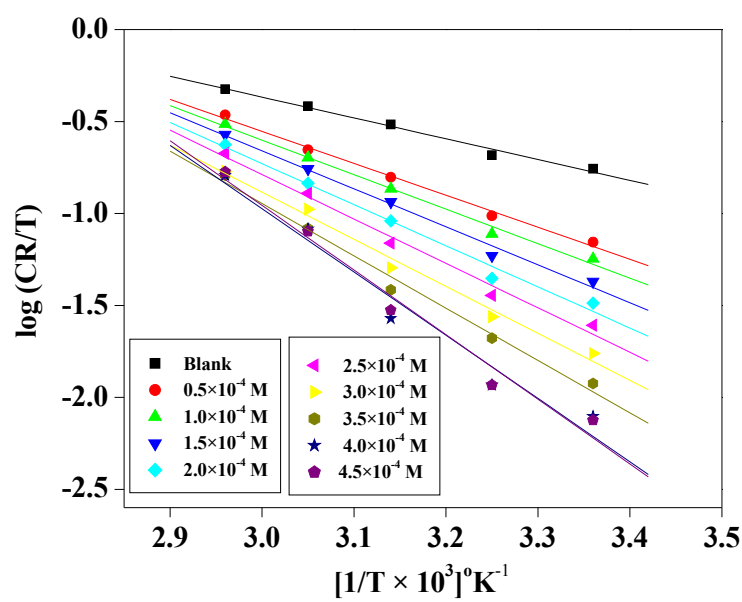

Figure 5: Transition state graph in the absence and presence of different concentrations of cefotaxime sodium for mild steel corrosion in $0.5 \mathrm{M}$ sulfuric acid. 


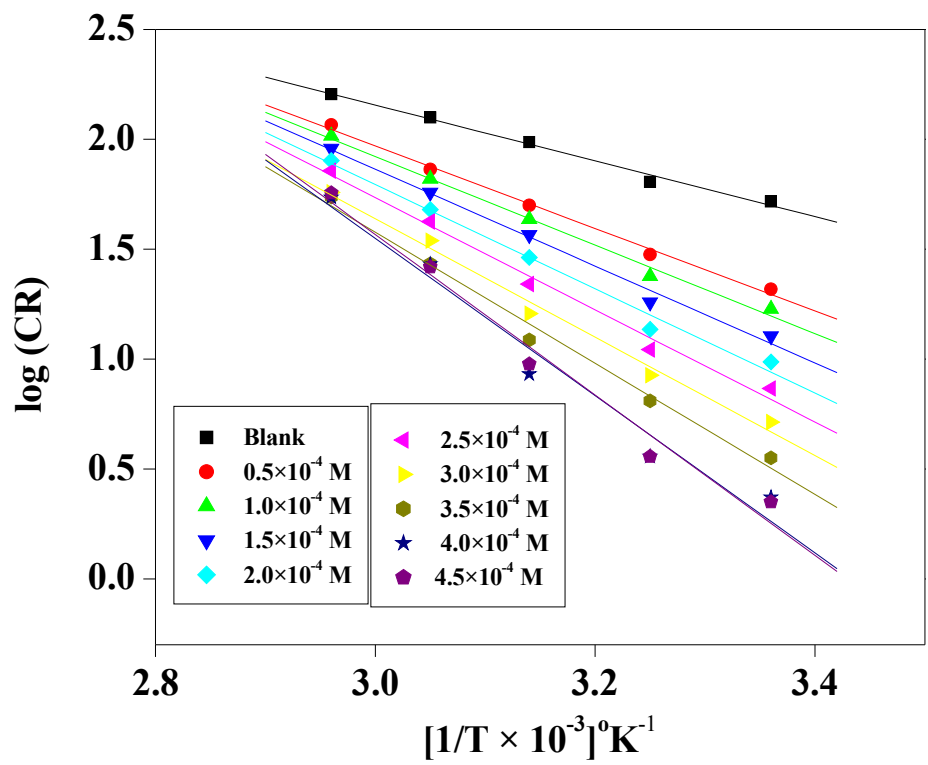

Figure 6: Arrhenius' plot of the cefotaxime sodium in $0.5 \mathrm{M}$ sulfuric acid solution.

\section{Activation parameters on the inhibition \\ process}

Temperature of the solution is key to understand the inhibitive process of corrosion. For observing the effect of temperature samples has been tested at 298 to $338 \mathrm{~K}$ for different concentrations of the cefotaxime sodium and inhibition efficiency and corrosion rate has been calculated and listed in Table 1 . Corrosion rate at various temperatures of solution and concentration of inhibitors are correlated with the Arrhenius equation to express the relationship of corrosion rate with the temperature of acidic media (37-40).

$$
\log \left(C_{r}\right)=\frac{-E_{a}}{2.303 R T}+\log \lambda
$$

Where $E_{a}=$ apparent effective activation energy, $\mathrm{R}=$ molar gas constant $\lambda=$ Arrhenius' pre exponential factor.

A graph of CR Vs. $1 / T$ has been plotted in Figure 6 which shows the regression coefficient approximately very close to unity. $E_{a}$ values are calculated from the slope of the curve. The slope of the curve is equivalent to $-E_{a} / 2.303 R$ and $\lambda$ value can be calculated from the intercept which is equivalent to the $\log \lambda$. Calculated values of these two has been listed in Table 3 . Value of activation energy is more than that of uninhibited sample and increasing though out the increment of the inhibitor concentration suggested that the adsorption of the inhibitor on the mild steel surface is physical adsorption. Subsequent increase in the activation energy also suggests that the inhibitor is less effective on increasing temperature towards the mild steel surface at $0.5 \mathrm{M}$ sulfuric acid medium. As per observation of Arrhenius equation it is found that the corrosion rate is also influence by $\lambda$ increasing the value decreases the corrosion rate (41).

Table 3: Thermodynamic parameters in absence and presence different concentration ranges of cefotaxime sodium for mild steel.

\begin{tabular}{|c|c|c|c|c|}
\hline $\begin{array}{l}\text { Concentration } \\
\text { of inhibitor }(M)\end{array}$ & $\begin{array}{l}E_{a} \\
\left(\mathrm{~kJ} \mathrm{~mol}^{-1}\right)\end{array}$ & $\begin{array}{l}\lambda \\
\left(\mathrm{mg} \mathrm{cm}^{-2}\right)\end{array}$ & $\begin{array}{l}\Delta H \\
\left(k^{J} \mathrm{~mol}^{-1}\right)\end{array}$ & $\begin{array}{l}\Delta S \\
\left(\mathrm{~J} \mathrm{~mol}^{-1} \mathrm{~K}^{-1}\right)\end{array}$ \\
\hline Blank & 24.29 & $9.14 \times 10^{5}$ & 21.68 & -142.25 \\
\hline $0.5 \times 10^{-4}$ & 35.92 & $3.95 \times 10^{7}$ & 33.30 & -110.93 \\
\hline $1.0 \times 10^{-4}$ & 38.54 & $9.10 \times 10^{7}$ & 35.92 & -103.99 \\
\hline $1.5 \times 10^{-4}$ & 42.19 & $2.98 \times 10^{8}$ & 39.58 & -94.12 \\
\hline $2.0 \times 10^{-4}$ & 45.41 & $8.11 \times 10^{8}$ & 42.80 & -85.81 \\
\hline $2.5 \times 10^{-4}$ & 48.86 & $2.45 \times 10^{9}$ & 46.25 & -76.60 \\
\hline $3.0 \times 10^{-4}$ & 51.58 & $5.24 \times 10^{9}$ & 48.96 & -70.29 \\
\hline $3.5 \times 10^{-4}$ & 57.11 & $3.35 \times 10^{10}$ & 54.50 & -54.86 \\
\hline $4.0 \times 10^{-4}$ & 68.49 & $1.90 \times 10^{12}$ & 65.88 & -21.27 \\
\hline $4.5 \times 10^{-4}$ & 69.91 & $3.32 \times 10^{12}$ & 67.30 & -16.65 \\
\hline
\end{tabular}

Value of enthalpy of activation $(\Delta \mathrm{H})$ and entropy of complex in transition state equation can be activation $(\Delta S)$ for the formation of the activated 
calculated by alternative Arrhenius equation i.e. transition state equation $(42,43)$

$$
C_{r}=\frac{R T}{N h} \exp \left(\frac{\Delta S}{R}\right) \exp \left(\frac{-\Delta H}{R T}\right)
$$

Where $\mathrm{h}=$ Planck's constant,

$\mathrm{N}=$ Avogadro's number,

$\Delta \mathrm{S}=$ entropy of activation

$\Delta \mathrm{H}=$ enthalpy of activation.

A graph of $\log (C R / T)$ versus $1 / T$ has been plotted as represented in Figure 5 which is a straight line. Values of enthalpy of activation $(\Delta \mathrm{H})$ and entropy of activation $(\Delta S)$ has been calculated from the slope and intercept of the curves and listed in Table 3. As per Table 3, in the inhibition process the value of the enthalpy is increasing with the increase in the inhibitor concentration. The positive value of enthalpy of activation reflects that the corrosion inhibition phenomenon is endothermic and dissolution of metal is difficult by increasing the inhibitor concentration (44). Higher protection efficiency is due to the presence of energy barrier for the reaction.

Entropy of activation $(\Delta S)$ is increasing with an increase in the inhibitor concentration as compared to the compared to free acid solution. Increased entropy of activation in the presence of inhibitor indicated that disorderness is increased on going from reactant to activated complex. Therefore the inhibition efficiency will increase.

\section{Linear Polarization technique}

Linear polarization data were listed in Table 4. Polarization resistance value increases with increase in inhibitor concentration results the increase in inhibition efficiency of the inhibitor used in the study. Maximum inhibition efficiency is approximately $93 \%$, which is in good agreement with the inhibition efficiency exhibited in the weight loss studies.

\section{Tafel Polarization}

Measurements of polarization have been measured and documented. Figure 6 shows plots demonstrating the effect of cefotaxime sodium concentrations on the anodic and cathodic polarization actions of mild stain in $0.5 \mathrm{M} \mathrm{H}_{2} \mathrm{SO}_{4}$ solution. Table 4 shows the electrochemical properties of plots, such as the density of corrosion current (Icorr), the potential for corrosion (Ecorr), the anodic slopes (ba and bc), the resistance to polarization ( $R p)$, and the inhibitor performance (IE percent) (45). As seen in Table 4, the addition of cefotaxime sodium to the $0.5 \mathrm{M} \mathrm{H}_{2} \mathrm{SO}_{4}$ solutions inhibit both anodic metal dissolution and cathode hydrogen evolution. Table 4 demonstrates that, when the concentration of cefotaxime sodium was increased, the inhibition of these reactions became more pronounced. Without causing major improvements in the tendency for corrosion, the inhibitor results in a lower $\mathrm{I}_{\text {corr }}$ corrosion current density, indicating that a mixed form inhibitor (i.e. prevents both anodic and cathodic corrosion) is adsorbed on the surface, preventing corrosion (46). Without an inhibitor, the ability of mild steel became involved and changed to $455 \mathrm{mV}$ (SCE) as a more negative value due to the dissolution of an airmolded oxide film, as seen in Figure 6 . With the addition of an inhibitor to the solution, the potential shifted to the positive side, and the shift became more pronounced as the inhibitor's concentration rose. The established Icorrdensity decrease was detected as cefotaxime sodium levels increased, indicating that the inhibitor's inhibitory efficacy increased as the inhibitor's concentration increased. This is the beginning of the production of protective oxide-and-cefotaxime films.

Table 4: Potentiodynamic polarization parameters for cefotaxime sodium in sulfuric acid medium on mild steel surface.

\begin{tabular}{|c|c|c|c|c|c|c|c|}
\hline \multirow[t]{2}{*}{$\begin{array}{l}\text { Inhibitor } \\
\text { Conc. }\end{array}$} & \multicolumn{5}{|c|}{ Tafel data } & \multicolumn{2}{|c|}{$\begin{array}{l}\text { Linear Polarization } \\
\text { data }\end{array}$} \\
\hline & $\begin{array}{l}-E_{\text {corr }} \\
(\mathrm{mV} \\
\text { SCE) }\end{array}$ & $\begin{array}{l}b_{a} \\
\left(m V \operatorname{dec}^{-1}\right)\end{array}$ & $\begin{array}{l}\mathbf{b}_{\mathrm{c}} \\
\left(\mathrm{mV} \mathrm{dec}^{-1}\right)\end{array}$ & $\begin{array}{l}I_{\text {corr }} \\
\left(\mu \mathrm{A} \mathrm{cm} \mathbf{c m}^{-2}\right)\end{array}$ & $\begin{array}{l}\text { IE } \\
(\%)\end{array}$ & $\begin{array}{l}R_{p} \\
\left(\Omega \mathrm{cm}^{2}\right)\end{array}$ & $\begin{array}{l}\text { IE } \\
(\%)\end{array}$ \\
\hline Blank & 455 & 63 & 137 & 1275 & - & 55.3 & - \\
\hline $1.0 \times 10^{-4}$ & 457 & 71 & 147 & 478 & 62.5 & 137.3 & 59.7 \\
\hline $2.0 \times 10^{-4}$ & 460 & 72 & 151 & 284 & 77.7 & 255.8 & 78.3 \\
\hline $3.0 \times 10^{-4}$ & 462 & 71 & 144 & 175 & 86.3 & 398.1 & 86.1 \\
\hline $4.0 \times 10^{-4}$ & 465 & 74 & 152 & 88 & 93.7 & 796.4 & 93.0 \\
\hline
\end{tabular}




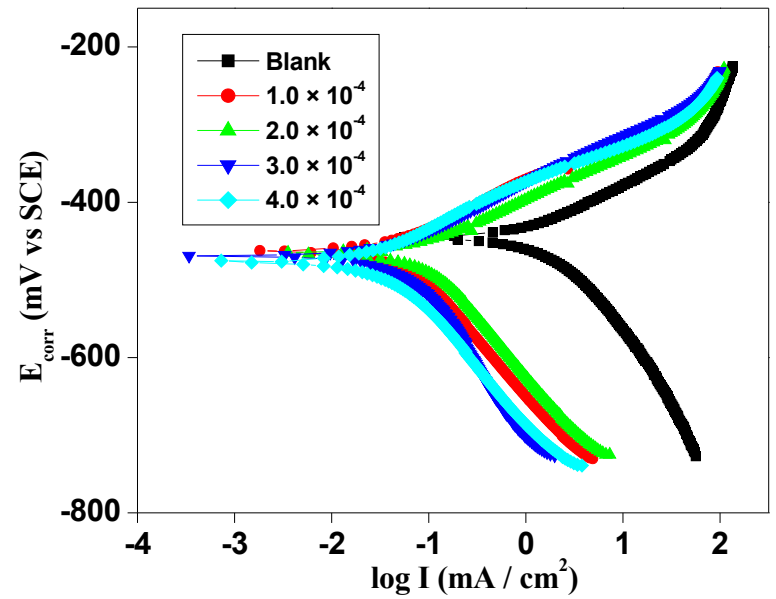

Figure 7: Tafel polarization curve with different concentrations of cefotaxime sodium on mild steel in $0.5 \mathrm{M}$ sulfuric acid.

Electrochemical Impedance Spectroscopy
techniques
Corrosion inhibition activity cefotaxime sodium was
investigated using electrochemical impedance
spectroscopy on mild steel surfaces in $0.5 \mathrm{M}$
aqueous $\mathrm{H}_{2} \mathrm{SO}_{4}$ solution. Figure 7 depicts an
impedance spectrum i.e. Nyquist plot mild steel
corrosion where the depressed semicircles look like
a depressed capacitive ring. A high frequency single
semicircle, which can be transmitted via the loading
phase of corrosion and the surface heterogeneity, is
due to these factors which can be exacerbated by
surface ruggedness, dislocations at the active site or
adsorption by the inhibitor molecules represented in
Figure 7. The impedance electrochemical data would
be compared to F. Mansfeld's multiple theoretical
circuits. The analogous circuit was applied at a

constant phase angle to demonstrate the impedance data applicable to the iron/acid interface model (47). For electrochemical impedance, the corresponding circuit parameters $\left(R_{s}, R_{t}, Y_{o}\right.$, and $n$ ) have been obtained and reported in Table 5 .

The inhibitor's adsorption effect is similar to the impedance distribution on the metal surface. Adsorption of drug inhibitor molecules causes polarization resistance $R_{p}$, which increases with the number of adsorbed molecules. Furthermore, the adsorbed inhibitor film reduces capacitance at the metal-solution interface as a result of a reduction in the dielectric constant between metal and electrolyte and/or an improvement in thickness of metal (48-50).

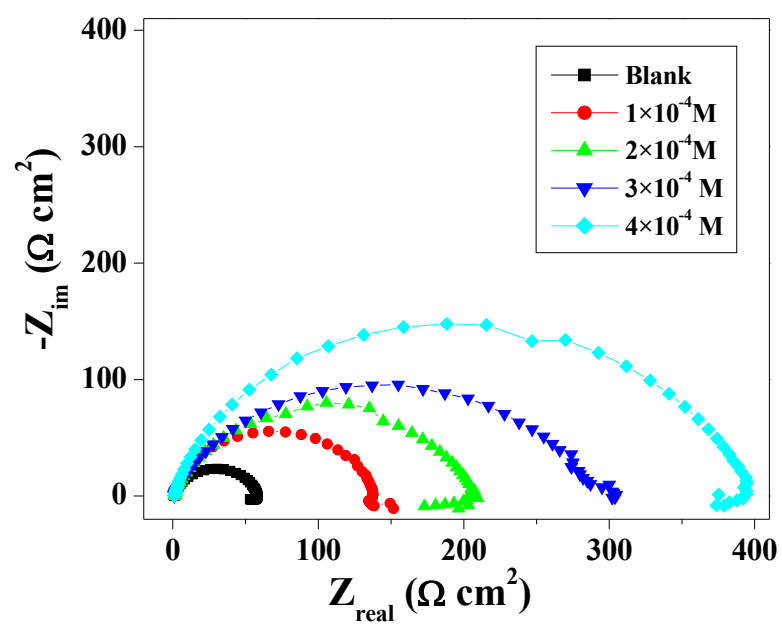

Figure 8: Nyquist plot of the electrochemical impedance spectroscopy curve of different concentrations of cefotaxime sodium on mild steel surface in $0.5 \mathrm{M}$ sulfuric acid. 
Table 5: Electrochemical impedance parameters values of cefotaxime sodium in 0.5M sulfuric acid

\begin{tabular}{|l|l|l|l|l|l|l|}
\hline $\begin{array}{l}\text { Inhibitor } \\
\text { concentration } \\
(\mathbf{p p m})\end{array}$ & $\begin{array}{l}\mathbf{R}_{\mathbf{s}} \\
\left(\mathbf{\Omega} \mathbf{~ c m}^{\mathbf{2}}\right)\end{array}$ & $\begin{array}{l}\mathbf{R}_{\mathbf{p}} \\
\left(\mathbf{\Omega} \mathbf{~ c m}^{\mathbf{2}}\right)\end{array}$ & $\begin{array}{l}\mathbf{Y}_{\mathbf{o}} \\
\left(\boldsymbol{\mu} \mathbf{F ~} \mathbf{c m}^{-2}\right)\end{array}$ & $\mathbf{N}$ & $\begin{array}{l}\mathbf{C}_{\mathbf{d l}} \\
\left(\boldsymbol{\mu F} \mathbf{c m}^{-2}\right)\end{array}$ & $\begin{array}{l}\text { IE } \\
(\mathbf{\%})\end{array}$ \\
\hline Blank & 1.13 & 53.3 & 1181.5 & 0.858 & 55 & - \\
\hline $1.0 \times 10^{-4}$ & 1.07 & 141.8 & 205.7 & 0.836 & 48 & 62.4 \\
\hline $2.0 \times 10^{-4}$ & 1.09 & 214.3 & 112.3 & 0.831 & 42 & 75.1 \\
\hline $3.0 \times 10^{-4}$ & 0.96 & 309.9 & 87.5 & 0.825 & 38 & 82.8 \\
\hline $4.0 \times 10^{-4}$ & 0.99 & 401.4 & 74.3 & 0.822 & 35 & 86.7 \\
\hline
\end{tabular}

\section{Surface Study (AFM)}

Atomic force microscopic technique is used to know morphology of the surface of mild steel unexposed in corrosive environment, exposed in corrosive environment without inhibitor and with optimum concentration of cefotaxime sodium inhibitor and the surface morphology is represented in Figure 8ac. Surface roughness of untreated, uninhibited, and inhibited surface of mild steel are $51 \mathrm{~nm}, 590 \mathrm{~nm}$, and $154 \mathrm{~nm}$, respectively. Decrease in surface roughness shows the effectiveness of the cefotaxime sodium.
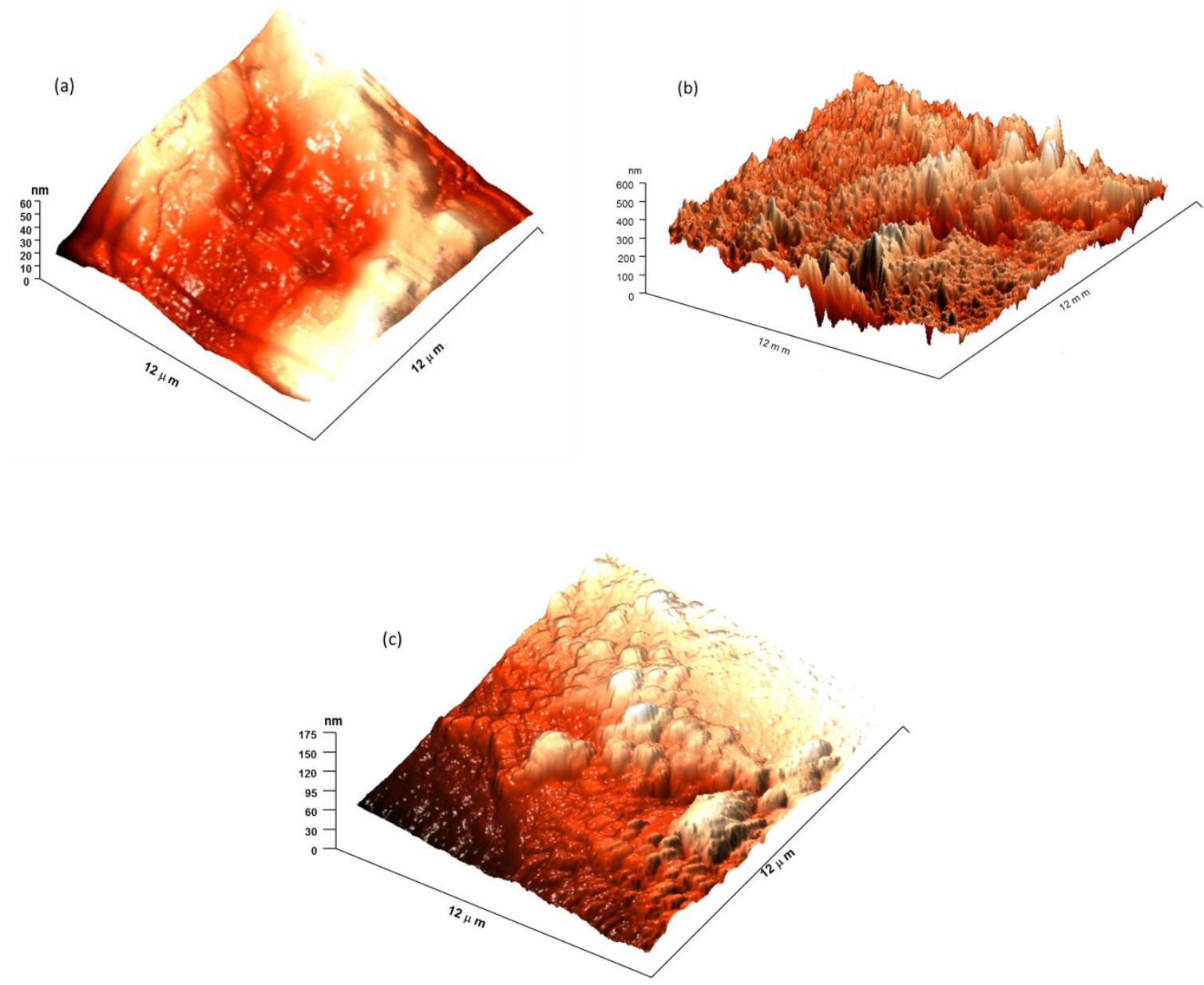

Figure 9: AFM studies of mild steel surface (a) polished surface, (b) surface exposed in corrosive medium without inhibitor, (c) surface exposed in corrosive medium with optimum concentration of cefotaxime sodium inhibitor.

\section{CONCLUSION}

- It is evident from all studies that cefotaxime sodium is good inhibitor for the surface of mild steel in $0.5 \mathrm{M}$ sulfuric acid medium.
- Increase in the temperature of the test solution results the decrease in the inhibitor efficiency suggest that it is a good inhibitor at lower temperature range. 
- $\quad$ Electrochemical studies suggested that it is a mixed type of inhibitor and adsorbed on the surface in monolayer.

- $\quad$ Adsorption of cefotaxime sodium follows Langmuir adsorption isotherm.

- All the thermodynamic and adsorption parameters suggested that the interaction of the inhibitor on mild steel surface is of the physical adsorption type.

\section{REFERENCES}

1. Adejoro IA, Ojo FK, Obafemi SK. Corrosion inhibition potentials of ampicillin for mild steel in hydrochloric acid solution. Journal of Taibah University for Science. 2015 Apr;9(2):196-202.

2. Sastri V. Types of corrosion inhibitor for managing corrosion in underground pipelines. Woodhead Publishing Limited; 2014.

3. Kuznetsov $Y$. Organic Inhibitors of corrosion of Metals. Thomas J, editor. Springer Science+ Business Media, LLC; 1996.

4. Roberge P. Handbook of Corrosion Engineering. 2nd Edition. McGraw-Hill Companies; 2012.

5. Kruger J. Cost of Metallic Corrosion. In: Revie RW, editor. Uhlig's Corrosion Handbook [Internet]. Hoboken, NJ, USA: John Wiley \& Sons, Inc.; 2011 [cited 2021 Sep 25]. p. 15-20. Available from: https://onlinelibrary.wiley.com/doi/10.1002/978047 0872864.ch2

6. Shukla SK, Quraishi MA. Cefacetrile as corrosion inhibitors for mild steel in acidic media J Electrochem Sci. 2011; 6:5689-5700

7. Anonymous. The Annual Cost of Corrosion to Ohio [Internet]. 2007. Available from: http://www.brown.senate.gov/imo/media/doc/Ohio Corrosion.pdf

8. Bhaskaran, R, Palaniswamy, N, Rengaswamy, NS. COST OF CORROSION AND CORROSION AUDITING IN INDIAN INDUSTRIES. Corrosion Reviews. 2009 Dec;27(Supplement):1-35.

9. NACE International. NACE-international Cost of corrosion study unveiled. Mater Perform. 2002; (July):20.

10. Ebenso EE, Khaled K, Shukla SK, Singh AK, Eddy N, Saracoglu $M$, et al. Quantum chemical investigations on quinoline derivatives as effective corrosion inhibitors for mild steel in acidic medium. Int J Electrochem Sci. 2012;

11. Raja PB, Ismail M, Ghoreishiamiri S, Mirza J, Ismail MC, Kakooei $S$, et al. Reviews on Corrosion
Inhibitors: A Short View. Chemical Engineering Communications. 2016 Sep 1;203(9):1145-56.

12. Dwivedi A, Bharti PK, Shukla SK. An overview of the polymeric material that can be used to prevent Metal corrosion: A Review. Journal of Turkish Chemical Society Section A: Chemistry, 2021; $8(3): 863-72$

13. Palou $\mathrm{R}$, Olivares-Xomelt $\mathrm{O}$, Likhanova $\mathrm{N}$. Environmentally Friendly Corrosion Inhibitors. In: Green Corrosion Inhibitors [Internet]. Hoboken, NJ, USA: John Wiley \& Sons, Inc.; 2011 [cited 2021 Sep 25]. p. 257-303. Available from: https://onlinelibrary.wiley.com/doi/10.1002/978111 8015438.ch7

14. Abdullah Dar M. A review: plant extracts and oils as corrosion inhibitors in aggressive media. Ind Lubrication and Tribology. 2011 Jun 21;63(4):22733.

15. Umoren SA. Polymers as Corrosion Inhibitors for Metals in Different Media - A Review. TOCORRJ. 2009 Jun 25;2(1):175-88.

16. Chigondo M, Chigondo F. Recent Natural Corrosion Inhibitors for Mild Steel: An Overview. Journal of Chemistry. 2016;2016:1-7.

17. Shukla SK. Corrosion inhibitive effect of N-(6methoxyquinolin-8-yl)-pentane-1, 4-diamine on mild steel/sulphuric acid solution interface. J Mater Environ Sci. 2015;6:1779-86.

18. Ji G, Shukla SK, Dwivedi P, Sundaram S, Ebenso EE, Prakash R. Parthenium hysterophorus plant extract as an efficient green corrosion inhibitor for mild steel in acidic environment. International Journal of Electrochemical Science. 2012;7(10):9933-45.

19. Gece G. Drugs: A review of promising novel corrosion inhibitors. Corrosion Science. 2011 Dec;53(12):3873-98.

20. Singh AK, Shukla SK, Quraishi MA. Corrosion behavior of mild steel in sulphuric acid solutionin presence of ceftazidime. Int. J. Electrochem. Sci. 2011; 6(11): 5802-14

21. Dwivedi A, Bharti P, Shukla S. Surface assimilation and corrosion inhibition characteristic of water soluble Polyvinyl Alcohol on mild steel surface in $0.5 \mathrm{M} \mathrm{HCl}$ solution. Journal of the Turkish Chemical Society Section A: Chemistry. 2021 Jan 11;219-30.

22. Reza I, Saleemi A, Naveed S. Corrosion inhibition of mild steel in $\mathrm{HCl}$ solution by Tinidazole. Polish Journal of Chemical Technology. 2011 Jan $1 ; 13(1): 67-71$. 
23. Singh AK, Shukla SK, Singh M, Quraishi MA. Inhibitive effect of ceftazidime on corrosion of mild steel in hydrochloric acid solution. Materials Chemistry and Physics. 2011 Sep;129(1-2):68-76.

24. Shukla SK, Quraishi MA. Ceftriaxone: a novel corrosion inhibitor for mild steel in hydrochloric acid. ] Appl Electrochem. 2009 Sep;39(9):1517-23.

25. Shukla SK, Quraishi MA. Cefalexin drug: A new and efficient corrosion inhibitor for mild steel in hydrochloric acid solution. Materials Chemistry and Physics. 2010 Mar;120(1):142-7.

26. Prasanna BM, Praveen BM, Hebbar $N$, Venkatesha TV, Tandon HC, Abd Hamid SB. Electrochemical study on inhibitory effect of Aspirin on mild steel in $1 \mathrm{M}$ hydrochloric acid. Journal of the Association of Arab Universities for Basic and Applied Sciences. 2017 Feb;22(1):62-9.

27. Shukla SK, Quraishi MA. The effects of pharmaceutically active compound doxycycline on the corrosion of mild steel in hydrochloric acid solution. Corrosion Science. 2010 Feb;52(2):31421.

28. Aronson JK, editor. Polystyrene sulfonates. In: Meyler's side effects of drugs: the international encyclopedia of adverse drug reactions and interactions. 16. ed. Amsterdam Boston Heidelberg: Elsevier; 20.

29. Shukla SK, Quraishi MA. Cefotaxime sodium: A new and efficient corrosion inhibitor for mild steel in hydrochloric acid solution. Corrosion Science. 2009 May;51(5):1007-11.

30. Salem H, Samir E. Determination of cefotaxime, cefoperazone, ceftazidime and cefadroxil using surface plasmon resonance band of silver nanoparticles. Braz J Pharm Sci [Internet]. 2018 Nov 29 [cited 2021 Sep 25];54(3). Available from: http://www.scielo.br/scielo.php?

script $=$ sci arttext\&pid $=$ S1984-

$82502018000300617 \&$ Ing =en\&tIng=en

31. SANKAR SA, Kumar AS, RAMESHKUMAR S. Corrosion Inhibition Of Mild Steel In $0.5 \mathrm{M} \mathrm{H} 2 \mathrm{SO} 4$ By 1-(2-Methyl-4-(2-Methylphenyldiazenyl) Phenyl) Azonapthalen-2-Ol. Am. J. Eng. Res. 2013; 2(9):1722.

32. Shukla SK, Quraishi MA. Effect of some substituted anilines-formaldehyde polymers on mild steel corrosion in hydrochloric acid medium. J Appl Polym Sci. 2011;n/a-n/a.

33. Tang L. A study of the polarisation techniques for corrosion rate measurement in a steel-concrete system. 9DBMC. 2002;158:1-10.
34. Harabor I, Nechifor G, Branzoi V, Branzoi F. Investigation of some organic polymers as corrosion inhibitors on carbon steel in cooling water systems. Univ Politeh Buchar Sci Bull Series B-Chem Mater Sci. 2016;78(3):145-60.

35. Ji G, Shukla SK, Ebenso EE, Prakash R. Argimone maxicana leaf extract for inhibition of mild steel corrosion in sulfuric acid solution. Int. J. Electrochem. Sci. 2013;8(8):10878-89.

36. Shukla $S$, Ebenso E. Corrosion inhibition, adsorption behaviour and thermodynamic properties of streptomycin on mild steel in hydrochloric acid medium. International Journal of Electrochemical Science. 2011;6:3277-91.

37. Khedr MGA, Lashien AMS. The role of metal cations in the corrosion and corrosion inhibition of aluminium in aqueous solutions. Corrosion Science. 1992 Jan;33(1):137-51.

38. Schorr M, Yahalom J. The significance of the energy of activation for the dissolution reaction of metal in acids. Corros Sci. 1972;867-8.

39. Umoren SA, Solomon MM, Udosoro II, Udoh AP. Synergistic and antagonistic effects between halide ions and carboxymethyl cellulose for the corrosion inhibition of mild steel in sulphuric acid solution. Cellulose. 2010 Jun;17(3):635-48.

40. Solomon MM, Umoren SA, Udosoro II, Udoh AP. Inhibitive and adsorption behaviour of carboxymethyl cellulose on mild steel corrosion in sulphuric acid solution. Corrosion Science. 2010 Apr;52(4):1317-25.

41. Szauer $T$, Brandt A. On the role of fatty acid in adsorption and corrosion inhibition of iron by amine - fatty acid salts in acidic solution. Electrochimica Acta. 1981 Sep;26(9):1257-60.

42. Abd El Rehim SS, Hassan $\mathrm{HH}$, Amin MA. Corrosion inhibition of aluminum by 1,1 (lauryl amido)propyl ammonium chloride in $\mathrm{HCl}$ solution. Materials Chemistry and Physics. 2001 Apr;70(1):64-72.

43. Ebenso EE. Synergistic effect of halide ions on the corrosion inhibition of aluminium in $\mathrm{H} 2 \mathrm{SO} 4$ using 2-acetylphenothiazine. Materials Chemistry and Physics. 2003 Mar;79(1):58-70.

44. Ebenso EE, Obot IB. Inhibitive properties, thermodynamic characterization and quantum chemical studies of secnidazole on mild steel corrosion in acidic medium. Int J Electrochem Sci. 2010;5(12):2012-35. 
45. Hermas A-EA, Elnady AM, Ali RM. Corrosion inhibition of stainless steel in sulfuric acid solution containing sulfide ions. ACMM. 2019 May $7 ; 66(3): 360-8$.

46. Madkour LH, Elshamy IH. Experimental and computational studies on the inhibition performances of benzimidazole and its derivatives for the corrosion of copper in nitric acid. Int J Ind Chem. 2016 Jun;7(2):195-221.

47. Murulana LC, Singh AK, Shukla SK, Kabanda MM, Ebenso EE. Experimental and Quantum Chemical Studies of Some Bis(trifluoromethylsulfonyl) Imide Imidazolium-Based Ionic Liquids as Corrosion Inhibitors for Mild Steel in Hydrochloric Acid Solution. Ind Eng Chem Res. 2012 Oct 10;51(40):13282-99.
48. Abd-El-Khalek DE, Hassan HHAM, Ramadan SR. Water-soluble sulfonated polyaniline as multifunctional scaling inhibitor for crystallization control in industrial applications. Chemical Engineering Research and Design. 2021 May;169:135-41.

49. Rahmani $H$, Meletis EI. Corrosion Inhibition of Brazing Cu-Ag Alloy with 1,2,3-Benzotriazole and 2,5-Dimercapto-1,3,4-Thiadiazole. Corrosion. 2021 Jan $1 ; 77(1): 29-39$.

50. Tsoeunyane MG, Makhatha ME, Arotiba OA. Corrosion Inhibition of Mild Steel by Poly(butylene succinate)-L-histidine Extended with 1,6diisocynatohexane Polymer Composite in $1 \mathrm{M} \mathrm{HCl}$. International Journal of Corrosion. 2019 Mar 3;2019:1-12. 